\title{
KEBIJAKAN FORMULATIF PENGATURAN \\ CYBERBULLYING SEBAGAI SALAH SATU BENTUK TINDAK PIDANA CYBERCRIME DI INDONESIA
}

Oleh :

Gde Aditya Waisnawa ${ }^{1}$

\begin{abstract}
Indonesia as a State of law is currently a crisis of legal products that put forward substantive justice for the litigants, it is understandable because some of the basic rules that contain material and formal criminal rules have been established long and may no longer be relevant to the application of the law in Indonesia today. Regardless of the controversial nature of government regulations in terms of social media conflicts related to Cyberbullying, respect for rights in expression and opinion should be realized and implemented correctly by the cyberspace. Amid the euphoria of the Indonesian people to welcome the presence of social media, must be in harmony with the spirit of behavior change by respecting and appreciating all forms of expression and opinion of someone, on the other hand the social media users should strive to be wise users when active in social media, because communication using text has the risk of misunderstanding is greater than using our five senses. the position of Article 27 paragraph (3) of the ITE Law is as lex specialis of Article 310 of the Criminal Code. Therefore, the interpretation of the norms contained in Article 27 paragraph (3) of the ITE Law regarding defamation and/or defamation cannot be separated from the criminal law norms contained in Article 310 and Article 311 of the Criminal Code. So this is the background and causes conflict because of overlapping rule of law in effect, causing legal uncertainty.
\end{abstract}

Keywords : Formulative Policy, Cyberbullying, Cybercrime

\begin{abstract}
Abstrak
Indonesia sebagai Negara hukum saat ini sedang krisis produk hukum yang mengedepankan keadilan substantif bagi yang berperkara, itu dapat dimaklumi dikarenakan beberapa peraturan pokok yang memuat aturan materiil dan formil pidana sudah dibentuk lama dan dimungkinkan tidak relevan lagi digunakan pada penerapan hukum di Indonesia saat ini. Terlepas dari masih kontroversialnya peraturan pemerintah dalam hal konflik di media sosial yang terkait dengan Cyberbullying, penghormatan Hak dalam berekspresi dan berpendapat sudah seharusnya disadari dan diimplementasikan dengan benar oleh para pengakses dunia maya. Pasal 27 ayat (3) UU ITE adalah sebagai lex specialis dari Pasal 310 KUHP. Maka, penafsiran norma yang termuat dalam Pasal 27 ayat (3) UU ITE mengenai penghinaan dan/atau pencemaran nama baik tidak bisa dilepaskan dari norma hukum pidana yang termuat dalam Pasal 310 dan Pasal 311 KUHP. Sehingga hal inilah yang melatarbelakangi dan menimbulkan konflik karena

1 Program Studi Magister (S2) Ilmu Hukum Universitas Udayana, Denpasar, Bali, email: waisnawa 6965@yahoo.co.id
\end{abstract}


tumpang tindihnya aturan hukum yang berlaku sehingga menyebabkan ketidak pastian hukum.

\section{Kata kunci : Kebijakan Formulatif, Cyberbullying, Cybercrime}

\section{PENDAHULUAN}

Kehadiran teknologi internet merupakan kebutuhan yang tidak dapat dihindarkan untuk menunjang pembangunan nasional. Hanya saja dibalik kemudahan dan kenyamanan layanan internet itu ada ancaman yang sangat merisaukan, yakni sisi keamanannya. Terkait hal tersebut, Sutraman berpendapat: "Pengamanan sistem informasi berbasis internet perlu diperhatikan, karena jaringan internet yang bersifat publik dan global sangat rentan dari berbagai kejahatan." Sehubungan dengan dampak dari kemajuan teknologi, Dikdik M. Arief dan Elisatris Gultom menyatakan bahwa: Sekalipun kemajuan teknologi informasi memberikan banyak kemudahan bagi kehidupan manusia, tetapi kemajuan ini pun secara bersamaan menimbulkan berbagai permasalahan yang tidak mudah ditemukan jalan keluarnya. Salah satu masalah yang muncul akibat perkembangan teknologi informasi adalah lahirnya kejahatan-kejahatan yang sifatnya 'baru' khususnya yang mempergunakan internet sebagai alat bantunya. Lazim dikenal dengan sebutan kejahatan di dalam dunia maya (Cybercrime), seperti Hacker, Pornografi, Cybersquating, dsb...

Beberapa bentuk kejahatan yang berhubungan erat dengan penggunaan Teknologi Informasi yang berbasis utama komputer dan jaringan telekomunikasi ini menurut Mas Wigrantoro Roes Setiadi, sebagaimana yang di kutip oleh Dikdik M. Arief dan Elisatris Gultom Cybercrime dapat dikelompokkan menjadi beberapa bentuk, yaitu Unauthorized access to computer system and service, Illegal contents, Data forgery, Cyber espionage, Cyber sabotage and extortion, Offence against intellectual property, Infingements of privacy. Upaya pengaturan Cybercrime dirintis sejak tahun 1977 dengan adanya pembentukan panitia khusus yang bertugas mengkaji penanganan Cybercrime. Sejak ditandatangani oleh negara-negara anggota G-8 pada 23 November 2001, CoC (Convention on Cybercrime) menjadi instrumen hukum internasional yang paling banyak dijadikan acuan utama dalam pembentukan peraturan perundangundangan mengenai tindak pidana Cyber oleh negara-negara di dunia, termasuk di Indonesia. Di Indonesia sendiri, upaya untuk menangani tindak pidana cyber telah dirumuskan dalam Undang-Undang Nomor 11 Tahun 2008 tentang Informasi dan Transaksi Elektronik.

Salahsatubentukdari Cybercrime yang tidak memiliki aturan hukum secara spesifik adalah Cyberbullying. Cyberbullying merupakan suatu perbuatan yang dilakukan oleh satu orang atau lebih dan bertujuan untuk menyakiti dan/atau menghina orang 
lain baik yang tidak dapat membela diri secara verbal ataupun nonverbal dan dilakukan secara terusmenerus dengan menggunakan media elektronik/teknologi digital. Dalam jangka panjang, korban bullying dapat menderita karena masalah emosional dan perilaku. Bullying dapat menimbulkan perasaan tidak aman, terisolasi, perasaan harga diri yang rendah, depresi atau menderita stress yang dapat berakhir dengan bunuh diri.

Pelaku Cyberbullying dapat melakukan aksinya tanpa konsekuensi dikarenakan setiap orang dalam dunia cyber bisa menjadi siapa saja dengan identitas apa saja. Untuk memidanakan pelaku Cyberbullying diperlukan aturan yang lebih spesifik yang mencakup seluruh aspek bullying dan cara-cara yang digunakan oleh pelaku. Ditambah lagi sulitnya sistem pembuktian karena data elektronik relatif mudah untuk diubah dan dipalsukan.

Permasalahan-permasalahan $\mathrm{di}$ ranah media sosial sebenarnya sudah diatur dalam Undang-Undang No.11 tahun 2008 tentang informasi dan transaksi elektronik, meskipun UU tersebut masih memiliki kelemahankelemahan yang dianggap belum secara benar di perlukan pengaturannya secara khusus di Indonesia. Ditinjau dari masalah regulasi, Indonesia belum sepenuhnya memiliki aturan yang mengatur secara rinci dan jelas tentang Cyberbullying.

Adapun aturan yang terkait dengan Cyberbullying masih terakomodasi secara umum di dalam Undang-Undang Nomor 11 Tahun 2008 tentang Informasi Teknologi dan Elektronik (ITE). Perbuatan yang dilarang di dalam UU ITE yang terkait dengan Cyberbullying tercantum dalam Pasal 27 ayat (1), ayat (3), dan ayat (4) dan Pasal 29. dalam UndangUndang Republik Indonesia Nomor 11 tahun 2008 tentang Informasi dan Transaksi Elektronik, terdapat pasalpasal yang lebih sesuai untuk jeratan para pelaku cyberbullying.

kontroversialnya peraturan pemerintah dalam hal konflik di media sosial yang terkait dengan Cyberbullying terkait dengan hal tersebut maka rumusan masalah yang akan diangkat yaitu pertama bagaimanakah pengaturan Cyberbullyingsebagaisalah satubentuk tindak Pidana dalam Hukum Positif di Indonesia?, kedua bagaimanakah pengaturan Kebijakan Formulasi di masa mendatang terhadap perbuatan Cyberbullying di Indonesia?.

Originalitas penelitian ini apabila melihat kemiripan dapat dilihat dari jurnal yang berjudul:

"Penegakan Hukum Terhadap Cybercrime Di Bidang Perbankan Sebagai Kejahatan Transnasional"2, yang disusun oleh Tri Kuncoro, dengan pembahasan kepada bentukbentuk tindak pidana cybercrime

2 Kuncoro, T. (2013). Penegakan Hukum Terhadap Cyber Crime Di Bidang Perbankan Sebagai Kejahatan Transnasional.Jurnal Magister Hukum Udayana (Udayana Master Law Journal), 2(3). doi:10.24843/ JMHU.2013.v02.i03.p08 
khususnya di bidang perbankan dan menitik beratkan kepada yuridiksi pengaturan hukum terhadap tindak pidana cybercrime khususnya di bidang perbankan. Sedangkan pada kemiripan yang kedua ditemukan pada jurnal dengan judul:

Keberadaan pemegang sahan dalam RUPS dengan system telecomfrence terkait jaringan yang bermasalah dalam prespektif cyberlaw" yang disusun oleh $\mathrm{Ni}$ Ketut Supasti Dharmawan ${ }^{3}$. Dengan pokok pembahasan penyelangaraan RUPS terkait jaringan hukum yang bermasalah ditinjau dari aspek Cyber Law, Sedangkan penelitian yang di angkat oleh penulis menitik beratkan kepada urgensi perlunya dibentuk undang-undang khusus mengenai Cyberbullying melalui formulasi kebijakan karena kekaburan norma yang terjadi.

Tujuan dari penelitian ini adalah untuk mengkaji bagaimana konsepsi dan aplikasi kedepanya untuk mencegah terjadinya tindak pidana Cybercrime di kemudian hari sebagai pembenar dijatuhkannya sanksi pidana dalam peradilan pidana di Indonesia.

\section{METODE PENELITIAN}

Penelitian ini tergolong kedalam jenis penelitian hukum normatif atau penelitian hukum kepustakaan, karena

3 Dharmawan, N. (2015). Keberadaan Pemegang Saham Dalam Rups Dengan Sistem Teleconference Terkait Jaringan Bermasalah Dalam Perspektif Cyber Law. Jurnal Magister Hukum Udayana (Udayana Master Law Journal), 4(1). doi:10.24843/JMHU.2015. v04.i01.p15 penelitian hukum ini dilakukan dengan cara meneliti bahan kepustakaan (library research) yang terdiri dari bahan hukum primer dan ditunjang oleh bahan hukum sekunder.

Menurut Soerjono Soekanto dan SriMamudji,penelitianhukumnormatif atau kepustakaan tersebut mencakup: Penelitian terhadap asas-asas hukum, Penelitian terhadap sistematik hukum, Penelitian terhadap taraf sinkronisasi vertikal dan horizontal, Perbandingan hukum, Sejarah hukum. ${ }^{4}$

Sehubungan dengan klasifikasi tersebut diatas maka penelitian hukum normatif menyangkut penelitian taraf sinkronisasi vertikal atas disharmonisasi norma yang ada antara KUHP dan beberapa undang-undang tindak pidana khusus dengan falsafah ideologi Pancasila.

Sesuai dengan karakteristik dan sifat penelitian kepustakaan, maka dalam penelitian ini akan memakai beberapa metode pendekatan, diantaranya : The Statue Approach (pendekatan perundang-undangan), The Analitical and Conseptual Approach (pendekatan analisis konsep hukum), The Comparative Approach (Pendekatan Perbandingan). Penelitian hukum jenis normatif, maka jenis bahan hukum yang lazim dipergunakan adalah Bahan-bahan Hukum Primer, Bahan-bahan hukum sekunder, Bahanbahan hukum tersier. $^{5}$

4 Soerjono Soekanto dan Sri Mamudji, 2001, Penelitian Hukum Normatif, Jakarta: PT. Raja Grafindo Persada, hlm. 14.

5 Ronny Hamijoyo Soemantri, 1998, Metode Penelitian Hukum dan Jurimetri, Jakarta: Ghalia Indonesia, hlm. 11-12 
Sehubungan dengan penelitian hukum normatif ini maka memakai sumber bahan hukum dari :

1. Bahan Hukum primer, seperti: KUHP, UU Terorisme, UU Narkotika, UU Psikotropika dan UU Pengadilan HAM

2. Bahan hukum sekunder, yakni memberikan penjelasan mengenai bahan hukum primer.

3. Bahan hukum tersier, menyangkut seperti kamus atau ensiklopedi, jurnal, majalah, dan internet.

Penelitianiniuntukpengumpulan bahan hukum memakai metode sistematis, yakni berupa pengumpulan bahan peraturan perundang-undangan.

Menggunakan teknis analitis seperti :

- $\quad$ Teknik diskripsi

- $\quad$ Teknik interpretasi

- $\quad$ Teknik evaluasi

- $\quad$ Teknik argumentasi

- $\quad$ Teknik sistematisasi

- $\quad$ Metode konstruksi hukum

\section{HASIL DAN PEMBAHASAN}

Peneliti disini hanya menampilkan hasil penelitian berupa analisis dari kajian secara deskriptif normatif. Melalui hasil kajian analisis atas masalah yang disajikan. Ada dua masalah pertama menyangkut analisis atas konsep dan aplikasi penerapan hukum terhadap pelaku cyberbullying dalam perundang-undangan pidana di Indonesia. Serta aplikasinya masih diberlakukan dengan kualifikasi khusus. Serta masalah kedua menyangkut pengaturan Kebijakan Formulasidimassamendatang terhadap perbuatan Cyberbullying tersebut.

\subsection{Kajian dan Analisis Cyberbullying dalam Teori Pemidanaan Hukum Tertulis di Indonesia}

Kebijakan formulatif yang digunakan Pengertian dan Ruang Lingkup Cyberbullying Sebagai Salah Satu Bentuk Tindak Pidana Kejahatan Internet di Indonesia. Dalam dunia maya pertukaran informasi dan komunikasi terjadi tanpa diperlukan kehadiran 2 orang atau lebih secara fisik yang dapat di jalin di tempat yang berbeda, kapan saja dan bahkan bisa saja salah satu orang yang berkomunikasi tidak tahu secara pasti siapa yang berdialog dengannya. Para remaja memiliki perilaku yang aktif dalam memakai layanan jejaring sosial. Mereka umumnya menggunakan internet bukan karena kebutuhan terhadap konten atau kebutuhan riset, tetapi mereka menganggap internet sebagai dunia yang penuh dengan aktivitas sosial yang menarik. Dalam Cyberbullying ada beberapa individu yang berperan, ada yang disebut pelaku, target, dan orang sekitar yang menyadari adanya bullying, komposisinya sama seperti bullying didunia nyata.

Bullies adalah pelaku dari Cyberbullying, entah bertujuan untuk melecehkan atau membalas kembali 
dengan melecehkan. Target adalah sasaran, sering kali diidentifikasi sebagai korban. Diluar pelaku dan target, ada individu lain yang tercakup suatu berpartisipasi mendukung bullying yang dinamakan dengan istilah Bystanders. ${ }^{6}$ Saat ini ketentuan Cybercrime di Indonesia banyak diatur dalam UU-ITE, walaupun UndangUndang tersebut sebagian besar adalah tentang transaksi elektronik daripada kejahatan Cyber. Sebelum diberlakukan UU-ITE, Cyber crime di Indonesia sudah diatur, namun masih tersebar di beberapa Undang-Undang. Namun demikian, setelah ada UUITE pun, ketentuan dalam beberapa UU tersebut tetap berlaku, antara lain sebagai berikut. Undang-Undang Republik Indonesia No.6 Tahun 1982 tentang Hak Cipta, kemudian diubah melalui Undang-Undang Republik Indonesia No.7 Tahun 1987 tentang Perubahan atas Undang-Undang Nomor 6 Tahun 1982 tentang Hak Cipta. Akhirnya pada perubahan kedua.

Berbagai pendapat para ahli menyatakan bahwa dewasa ini sebagai perkembangan kejahatan model baru seiring dengan kemajuan ilmu pengetahuan dan teknologi komunikasi dan informasi canggih berdampak langsung pada modus operandi kejahatan yang menyertainya.

Kejahatan inkonvesional dimaksud seperti tindak pidana korupsi, terorisme, pencucian uang,

6 Salman Luthan, 2016, Asas dan Kriteria Kriminalisasi kejahatan mayantara, Jurnal Hukum, FHK2H, Surabaya, hlm 78. narkotika, kejahatan menghilangkan nyawa orang dan modusnya. Tampak bahwa tindak - tindak pidana atas kejahatan dengan ciri dan karakter seperti tersebut diatas bahwa perspektif penegakan hukumannya memerlukan penanganan serius dan terpadu. Upaya penegakan hukumnya mulai dari usaha preemtif, preventif dan represif.

\subsection{Interpretasi Futuristik Anti- sipatif Terhadap Urgensi Kebijakan Formulatif Sehu- bungan Dengan Tindak Pidana Cyber Bullying Sebagai Salah Satu Bentuk Tindak Pidana Cybercrime di Indonesia}

Tindakan CyberBullying memiliki dampak-dampak negatif bagi para korbannya, khususnya dampak psikologis yang dapat membuat korbannya kehilangan kepercayaan dirinya dan dampak psikologis terburuk adalah hasrat korban untuk mengakhiri hidupnya. Cyberbullying sudah dinilai sebagai suatu permasalahan yang harus mendapatkan perhatian yang lebih dari para penegak hukum, karena kasusnya yang semakin marak terjadi baik di dunia internasional maupun di Indonesia. Telah adanya suatu definisi yang komprehensif mengenai CyberBullying di dalam Massachussetts Law memberikan suatu batasan-batasan dan kategorisasi untuk mengidentifikasi suatu tindakan Cyber Bullying. ${ }^{7}$ Dalam hukum positif di Indonesia, fenomena Cyber Bullying dimasukkan ke dalam

7 Barda Nawawi, Op.Cit. hlm 395 
definisi pencemaran nama baik atau penghinaan dimana definisi tersebut dirasa kurang memadai jika melihat unsur-unsur Cyber Bullying yang begitu luas dan memiliki berbagai jenis yang lebih dari sekadar pencemaran nama baik.

Ketidak lengkapan definisi tersebut dapat menjadikan siapapun menjadi pelaku CyberBullying, bahkan aktivitas jurnalistik yang sejatinya merupakan penjaminan akan hak kebebasan untuk menyebarluaskan opini kepada publik pun dapat dinilai sebagai pencemaran nama baik bagi mereka yang merasa dicemarkan nama baiknya. Bahkan di beberapa negara, kasus penghinaan atau pencemaran nama baik telah dimasukkan ke dalam ranah perdata karena hal tersebut merupakan konflik antar individu. Indonesia yang masih memasukkan perbuatan pencemaran nama baik dan penghinaan di dalam hukum pidana memiliki hukuman yang dinilai cukup berat. Pasal yang dapat digunakan untuk menjerat pelaku Cyber Bullying adalah Pasal 310 dan 311 KUHP dan Pasal 27 ayat (3) UU ITE tentang pencemaran nama baik. Tindak pidana pencemaran nama baik dalam KUHP diatur sebagai delik aduan dimana harus adanya suatu aduan dari korban yang merasa telah dicemarkan nama baiknya agar si pelaku dapat dijerat oleh pasal tersebut.

Perancang UU ITE tidak mengikuti perkembangan hukum internasional. Sedikitnya 50 negara sudah mengalihkan masalah kabar bohong, penghinaan, pencemaran, dari hukum pidana menjadi hukum perdata. Beberapa negara bahkan menghapus sama sekali ketentuan hukum penyebaran kebencian dan penghinaan karena dianggap sulit dibuktikan atau sangat subjektif. Dengan ancaman hukuman penjara lebih dari enam tahun, aparat kepolisian dapat menahan setiap orang, termasuk wartawan, yang dianggap melakukan penyebaran berita bohong seperti diatur dalam UU ITE. Seperti yang terjadi pada kasus yang melatarbelakangi dikeluarkannya Putusan MK Nomor 50/PUU-VI/2008, seorang jurnalis yang merasa hakhak kebebasan berpendapatnya yang dijamin oleh UUD 1945 telah dikekang oleh keberadaan UU ITE mengajukan Judicial Review terhadap Pasal 27 ayat (3) UU ITE yang menurutnya bertentangan dengan kaidah-kaidah yang melindungi hak kebebasan berpendapat dan juga unsur yang terkandung dalam pasal tersebut telah diatur dalam KUHP yang memiliki perumusan unsur delik yang lebih rinci dan lebih memperlihatkan delik materiil.

Mahkamah Konstitusi berpendapat bahwa Pasal 27 ayat (3) UU ITE tidak bertentangan dengan UUD 1945 dan dalam menghadapi perkembangan teknologi yang begitu pesat dibutuhkan suatu pengaturan khusus (lex specialis) untuk melindungi hakhak para pengguna internet yang unsur-unsur dalam KUHP dianggap kurang memadai dan tidak dapat menjangkau ranah online. Pada 
putusannya, Mahkamah Konstitusi menolak permohonan yang diajukan oleh pemohon karena menurut pertimbangan Mahkamah.

Konstitusi Pasal 27 ayat (3) UU ITE dirasa tidak perlu dipertanyakan konstitusionalitasnya. Akibat yang ditimbulkan dari Putusan Mahkamah Konstitusi adalah sifat putusannya yang mengikat bagi semua orang dan badan hukum yang ada di Indonesia, hal ini berbeda dengan putusan peradilan pada umumnya. Dampak bagi masyarakat di Indonesia adalah masyarakat menjadi lebih terbatas dan hati-hati dalam menyalurkan pendapat atau dalam menggunakan media elektronik sebagai sarana transaksi maupun komunikasi. Hal tersebut membuktikan bahwa kebebasan berpendapat dan sifat anonimitas yang disalahgunakan sebagai perangkat penyedia imunitas dari hukum merupakan dua aspek yang saling bertentangan dan membutuhkan perhatian baik dari segi sosiologis, konstitusional, maupun yuridis.

Pendapat Mahkamah Konstitusi menyatakan bahwa dalam Pasal 310 dan 311 KUHP terdapat unsur "di muka umum" dianggap kurang memadai sehingga perlu rumusan khusus yang bersifat ekstensif yaitu "mendistribusikan, mentransmisikan dan/atau membuat dapat diaksesnya" adalah tepat sepanjang maksudnya ialah bahwa penghinaan dalam dunia cyber tidak dapat dilakukan di muka umum dalam konteks yang konvensional yang terjadi dalam dunia nyata, yaitu di hadapan orang banyak secara fisik. Pasal 310 dan 311 KUHP merupakan pengaturan yang dibuat dalam zaman paper based dan pembuat undang-undang pada waktu itu belum memikirkan bahwa, perkembangan teknologi dapat memfasilitasi tindak pidana penghinaan yang paperless, seperti dalam internet. Oleh karena itu, penghinaan yang diatur dalam KUHP dinilai tidak dapat menjangkau delik penghinaan dan pencemaran nama baik di dunia cyber. Tetapi di sisi lain, urgensi Pasal 27 ayat (3) UU ITE bukanlah terletak pada tidak dapat dipenuhinya unsur "di muka umum" sebagaimana dimaksud dalam Pasal 310 KUHP, tetapi pada bentuk "di muka umum" yang dimaksud dalam Pasal 27 ayat (3) UU ITE ialah dalam konteks cyberspace, yaitu informasi dan dokumen elektronik tersebut dapat diakses oleh umum sehingga dengan demikian dapat diketahui oleh umum. Selain itu, rumusan pasal Pasal 27 ayat (3) UU ITE telah memberikan perlindungan dengan mengatur unsur "dengan sengaja" dan "tanpa hak" sebagai penyesuaian perkembangan di bidang teknologi informasi dan ketentuan seperti itu diperlukan sebagai salah satu cara untuk menutup kelemahan hukum tertulis agar dapat mengikuti perkembangan masyarakat atau perkembangan teknologi informasi. Terminologi "mendistribusikan, mentransmisikan, atau membuat dapat diaksesnya informasi elektronik atau dokumen elektronik" esensinya adalah penyebaran materi penghinaan dengan menggunakan cara baru 
atau modus operandi baru dengan memanfaatkan media elektronik. Oleh karena itu, unsur "mendistribusikan, mentransmisikan, dan membuat dapat diaksesnya" ialah tindakan-tindakan dalam dunia cyber yang dapat mencapai pemenuhan unsur "di muka umum" atau "diketahui umum". Selain itu, kedudukan Pasal 27 ayat (3) UU ITE adalah sebagai lex specialis dari Pasal 310 KUHP. Maka, penafsiran norma yang termuat dalam Pasal 27 ayat (3) UU ITE mengenai penghinaan dan/atau pencemaran nama baik tidak bisa dilepaskan dari norma hukum pidana yang termuat dalam Pasal 310 dan Pasal 311 KUHP. Demikian juga dengan CyberBullying yang ditujukan pada pribadi dan tidak disebarkan melalui media yang dapat diakses oleh umum, unsur "di muka umum" tidak terpenuhi sehingga tidak dapat dijerat oleh Pasal 27 ayat (3) UU ITE. Tetapi secara umum, tindakan CyberBullying yang dilakukan di media elektronik/ dunia cyber pada media sosial yang dapat diakses oleh publik akan dapat dijerat oleh hukum karena memenuhi unsur "di muka umum". Menyikapi penggunaan Pasal 27 ayat (3) UU ITE untuk menjerat pelaku bullying dimana pun ia berada, maka terungkaplah kelebihan UU ITE dibandingkan dengan KUHP dimana UU ITE mampu melindungi hak-hak para pengguna internet di Indonesia dengan adanya perluasan yurisdiksi dan kejelasan perumusan dari penghinaan yang bersifat online.

\section{KESIMPULAN}

Penyelesaian perkara Cyber Bullying secara tegas terdapat dan diatur dalam Pasal 27 ayat (3) UU ITE, Pada dasarnya Pasal 27 ayat (3) UU ITE merupakan lex specialis dari KUHP sebagai lex generalis yang membuat Pasal 27 ayat (3) UU ITE tidak dapat dipisahkan dari norma hukum pokok yang terdapat pada Pasal 310 KUHP, kenyataannya Undangundang No.11 Tahun 2008 tentang informasidantransaksielektronik, yang diteliti masih memiliki kelemahankelemahan karena dianggap tumpang tindih dan belum mengatur secara rinci dan jelas baik secara tertulis dan penerapannya terhadap Cyberbullying. Dengan berkembangnya jaman, untuk menghadapi Fenomena Cyber Bullying Pengaturan terhadap kejahatan berdimensi baru yang beraspek global maupun bersifat transnasional, mutlak diperlukan apabila ditempatkan pada keseluruhan peraturan hukum pidana nasional mencakup peraturan hukum pidana umum dalam KUHP guna menanggulangi kejahatan berdimensi baru seperti kejahatan komputer dan kejahatan internet (cyber crime) diperlukan suatu peraturan yang lebih khusus, guna meminimalisir ataupun mencegah terjadinya kejahatan terhadap dunia maya (Cybercrime). 


\section{DAFTAR PUSTAKA}

\section{BUKU}

Ali, Achmad. (2011). Menguak Tabir Hukum, Cetakan Ketiga, Ghalia Indonesia, Bogor.

Ali, Z. (2010). Metode penelitian hukum, cet. Ke-2, Jakarta: Sinar Grafika. Jakarta.

Arief, B. N. (2006). Tindak Pidana Mayantara. Raja Grafindo Persada, Jakarta.

Arief, D. M., \& Gultom, E. (2005). Cyber Law Aspek Hukum Teknologi Informasi. Bandung: Refika Aditama.

Bhakti, Y. (2000). Penafsiran dan Konstruksi Hukum. Alumni, Bandung.

Chazawi, A., \& Shifia, A. (2009). Tindak pidana: pornografi. Putra Media Nusantara (PMN).

Gunarsa, A., \& Sidharta, B. A. (2013). Meuwissen tentang pengembanan hukum, ilmu hukum, teori hukum, dan filsafat hukum.

Hadjon, P. M., \& Djatmiati, T. S. (2005). Argumentasi hukum. Penerbit Gajah Mada University Press, Yogyakarta.

Kusumo, S. M., \& Pitlo, M. A. (1993). Bab-Bab Tentang Penemuan Hukum.

Leyh, G. (2008). Hermeneutika Hukum: Sejarah. Teori, dan Praktik (terjemahan oleh $M$. Khazim), Bandung: Nusa Media.
Losey, B. (2011). Bullying, Suicide, and Homicide: Understanding, Assessing, and Preventing Threats to Self and Others for Victims of Bullying. Routledge. New York.

Marpaung, L. (2005). Asas-TeoriPraktik Hukum Pidana. Sinar Grafika, Jakarta.

Mertokusumo, S. (2009). Penemuan Hukum Sebuah pengantar, liberty. Yogyakarta, cet, 6 .

Moerad, H. P. (2005). Pembentukan hukum melalui putusan pengadilan dalam perkara pidana. Alumni. Bandung

Priyatna, A. (2010). Let's End Bullying: Memahami, Mencegah, dan Mengatasi Bullying. PT. Elex Media Komputindo. Jakarta.

Rifai, A. (2010). Penemuan hukum oleh hakim: dalam perspektif hukum progresif. Sinar Grafika. Jakarta.

Riswandi, B. A. (2003). Hukum dan internet di Indonesia. UII Press. Yogyakarta.

Shidarta. (2006). Karakteristik penalaran hukum dalam konteks keindonesiaan. CV. Utomo.

Sitompul, J. (2012). Cyberspace, Cybercrimes, Cyberlaw: Tinjauan Aspek Hukum Pidana. PT Tatanusa. Jakarta.

Sidharta, B. A. (1999). Refleksi Tentang Struktur Ilmu Hukum Sebuah Penelitian tentang fundasi Kefilsafatan dan Sifat Keilmuan Ilmu Hukum sebagai 
Landasan Pengembangan Ilmu Hukum Nasional Indonesia. Mandar Maju. Bandung.

Sudikno, M. (2005). Mengenal Hukum Suatu Pengantar.

Soekanto, S. (2006). Pengantar penelitian hukum. Penerbit Universitas Indonesia (UIPress). Jakarta.

Sulianta, F. (2010). Cyberporn: bisnis atau kriminal. Elex Media Komputindo. Jakarta.

Sutarman, H., Widiana, I. G., \& Amin, I. (2007). Cyber crime: modus operandi dan penanggulangannya. LaksBang Pressindo. Jogjakarta.

Wahid, A., \& Labib, M. (2005). Kejahatan Mayantara (cyber crime). Refika Aditama. Jakarta.

Walden, I. (2007). Computer crimes and digital investigations ( $\mathrm{p}$. 01). Oxford: Oxford University Press. New York.

\section{PERATURAN}

\section{PERUNDANG - UNDANG}

Kitab Undang-Undang Hukum Pidana.

Undang Undang Nomor 11 Tahun 2018 Tentang Informasi dan Transaksi Elektronik

Undang undang Nomor 48 tahun 2009 Tentang Kekuasaan Kehakiman

\section{DESERTASI}

Wisnubroto, A. (1997). KEBIJAKAN HUKUM PIDANA DALAM $P E N A N G G U L A N G A N$
$P E N Y A L A H G U N A A N$ KOMPUTER (Doctoral dissertation, PROGRAM PASCASARJANA UNIVERSITAS DIPONEGORO).

\section{PERTEMUAN ILMIAH}

Shidarta,, "Penemuan Hukum Melalui Putusan Hakim", Makalah dibawakan pada Seminar Pemerkuatan Pemahaman Hak Asasi Manusia Untuk Hakim Seluruh Indonesia di Hotel Grand Angkasa, Komisi Yudisial, Medan, 2 - 5 Mei 2011.

\section{ARTIKEL JURNAL}

Kuncoro, T. (2013). Penegakan Hukum Terhadap Cyber Crime Di Bidang Perbankan Sebagai Kejahatan Transnasional.Jurnal Magister Hukum Udayana (Udayana Master Law Journal), 2(3). doi:10.24843/JMHU.2013. v02.i03.p08.

Dharmawan, N. (2015). Keberadaan Pemegang Saham Dalam Rups Dengan Sistem Teleconference Terkait Jaringan Bermasalah Dalam Perspektif Cyber Law. Jurnal Magister Hukum Udayana (Udayana Master Law Journal), 4(1). doi:10.24843/ JMHU.2015.v04.i01.p15. 